\title{
Эквализация оптического сигнала в дисперсионной оптической линии связи с помощью синтетической фотонной решетки
}

\author{
$\underline{\text { А.В. Паньков }}^{1, *}$, О.С. Сидельников ${ }^{1}$, И.Д. Ватник ${ }^{1}$, А.А. Сухоруков ${ }^{2}$, Д.В. Чуркин ${ }^{1}$ \\ ${ }^{1}$ Новосибирский государственный университет \\ ${ }^{2}$ Nonlinear Physics Centre, Research School of Physics, Australian National University, Canberra, ACT \\ 2601, Australia \\ *E-mail: dabrdadub@mail.ru
}

DOI: 10.31868/RFL2020.132-133

На сегодняшний день наблюдается экспоненциальный рост объемов интернет-трафика, в то же время современные волоконно-оптические линии связи уже приближаются к пределу своей пропускной способности [1]. Приобретающим популярность способом увеличения пропускной способности является пост-обработка оцифрованного сигнала с помощью методов машинного обучения, в том числе с помощью искусственных нейронных сетей [2]. Основной проблемой в этих методах является увеличение скорости обработки, поскольку для применений необходимо обрабатывать сигнал в режиме реального времени. С другой стороны, реализация нейронной сети не обязательно должна быть программной - обработка информации может происходит непосредственно в оптическом диапазоне с помощью управления оптическими импульсами.

В данной работе изучается возможность эквализации сигнала в оптической линии связи с помощью полностью оптической обработки с использованием оптической нейронной сети на основе синтетической фотонной решетки (СФР) системы, состоящей из двух оптоволоконных колец различной длины, соединенных оптоволоконным делителем. Из-за разницы в длине петель импульс, помещенный в одну из них, создает последовательность импульсов в каждой из петель, которые интерферируют при каждом обороте, тем самым создавая комплексную картину эволюции, которая управляется с помощью контроля набега фаз и введения управляемого усиления или затухания в петлях [3]. Нами было показано, что подбор параметров СФР для получения заданной эволюции сигнала можно производить методами, аналогичными методам построения искусственных нейронных сетей. При этом нейронная сеть на основе СФР работает с временной последовательностью оптических сигналов в волокне, что делает возможным использование этого вида искусственной нейронной сети для обработки телекоммуникационного сигнала.

В данной работе мы исследуем процесс компенсацию дисперсионного уширения импульсов в линейном оптическом канале с затуханием и дисперсией с помощью синтетической фотонной решетки. Эквализация сигнала в таком случае производится линейным преобразованием временной последовательности импульсов. Такое преобразование может быть реализовано в оптоволоконной системе с помощью СФР при правильном подборе ее параметров.

Мы использовали линейное уравнение Шредингера для моделирования распространения сигнала с модуляцией 16-QАМ в оптической линии длиной 100 км. Полученный в результате искаженный сигнал подавался на вход синтетической фотонной решетки, и производилось моделирование эволюции последовательности импульсов в процессе их циркуляции внутри СФР. При этом подбирались такие параметры синтетической фотонной решетки, чтобы после некоторого числа ее обходов на выходе из решетки воспроизводился сигнал, 
наиболее близкий к исходному, т.е. сигналу в начале оптической линии. Подбор параметров производился методом градиентного спуска.

Качество восстановления сигнала определялось по диаграммам сигнальных созвездий (рис. 1) в комплексной плоскости. Пост-обработка сигнала с помощью СФР позволила видоизменить сигнальное созвездие, приблизив его к начальному прямоугольному распределению. Однако качественное восстановление сигнала не достигается. Это может быть связано особенностями реализации синтетической фотонной решетки - а именно циркулированию энергии между короткой и длинной петлей, что затрудняет подбор необходимых параметров СФР.

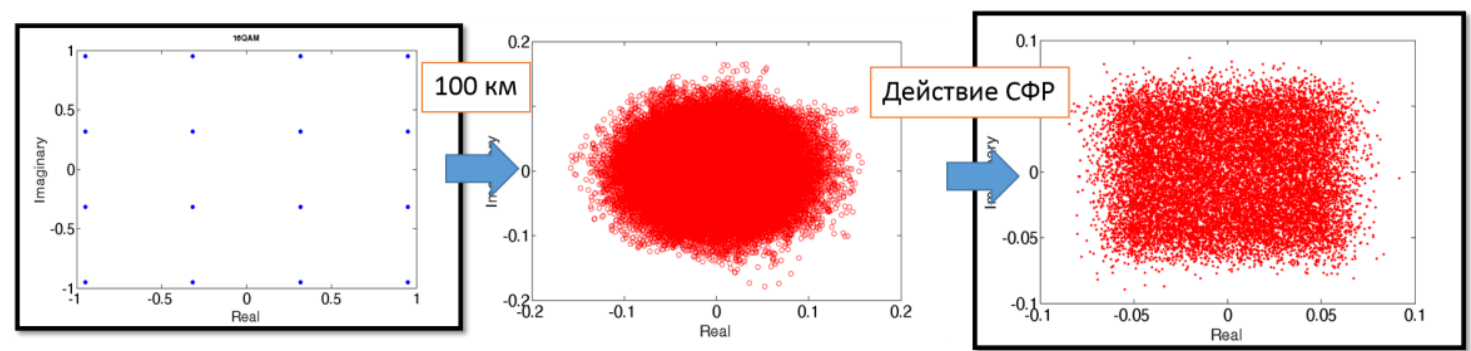

Рис. 1. Диаграммы сигнального созвездия: слева - для исходного сигнала, в центре - после прохождения дисперсионной линии с затуханием, справа - после обработки с помощью синтетической фотонной решетки.

Работа выполнена в рамках государственного задания FSUS-2020-0034.

\section{Литература}

[1] R. Tkach, Bell Labs Tech. J. 14, 3-9 (2010)

[2] O. Sidelnikov, A. Redyuk, and S. Sygletos, Opt. Express 26, 32765 (2018)

[3] A. V. Pankov, et. al. Sci. Rep. 9, 3464 (2019) 